\title{
Is the clinical course of laryngeal typical carcinoid tumor indolent?
}

\author{
Alfio Ferlito $\cdot$ Kenneth O. Devaney \\ Jennifer L. Hunt · Alessandra Rinaldo
}

Received: 27 August 2013/Accepted: 29 August 2013/Published online: 8 September 2013

(C) Springer-Verlag Berlin Heidelberg 2013

Neuroendocrine neoplasms of the larynx constitute the second most common group of neoplasms of this organ after squamous cell carcinoma [1]. Tumors with neuroendocrine morphology are a distinct subset of laryngeal neoplasms that share specific morphologic, histochemical, immunohistochemical, and ultrastructural characteristics. They can be conveniently divided into two main groups: those of epithelial origin and those of neural type (which includes only paraganglioma). Recently, a more succinct categorization for the first group has been supported by multiple authors, which includes separating the tumors into four histologic types based on the histopathological characteristics: typical carcinoid tumor, atypical carcinoid tumor, small cell neuroendocrine carcinoma, and large cell neuroendocrine carcinoma. While this new classification does provide better risk stratification and more useful information for treatment, others have advocated for using the terminology of well-differentiated neuroendocrine carcinoma, moderately-differentiated neuroendocrine carcinoma in place of the typical and atypical carcinoid.

As background, typical carcinoid tumor is the least common of the laryngeal neuroendocrine neoplasms and

This paper was written by members of the International Head and Neck Scientific Group (http://www.IHNSG.com).

A. Ferlito $(\bowtie) \cdot$ A. Rinaldo

ENT Clinic, University of Udine, Piazzale S. Maria della

Misericordia, 33100 Udine, Italy

e-mail: a.ferlito@uniud.it

K. O. Devaney

Department of Pathology, Allegiance Health, Jackson, MI, USA

J. L. Hunt

Department of Pathology, University of Arkansas for Medical

Sciences, Little Rock, AR, USA often arises in the supraglottis and especially in the arytenoid and in the aryepiglottic fold. The tumor is most often identified in the seventh decade of life [2, 3]. The main issue with the proposed nomenclature arises when one examines the clinical course of the typical carcinoid tumor of the larynx. The name "typical carcinoid" implies to most that the lesion will have an indolent course. But, this is most certainly not the case for these larynx tumors. Although in the larynx they rarely present with lymph node metastases at the time of the clinical diagnosis, these tumors eventually metastasize in approximately one-third of cases [4, 5]. Soga et al. [6] observed that $33 \%$ of 42 patients with so-called typical carcinoid tumor of the larynx recorded in the Niigata Registry for Gut-Pancreatic Endocrinomas [3] developed metastases. As well, Batsakis et al. [7] reported an incidence of distant metastases in $30.7 \%$ of cases of typical carcinoid tumor of the larynx (four of 13 patients)-moreover, one patient ultimately died of disease. We believe that these statistics greatly exceed most viewer's expectations of the behavior of an "indolent tumor". Wenig and Gnepp [8] reported a case of typical carcinoid tumor of the larynx associated with carcinoid syndrome which developed after multiple liver nodules were detected; one of these nodules was biopsied and proved to be morphologically identical to the laryngeal neoplasm. This patient had increased 5-hydroxyindoleacetic acid (5-HIAA) levels in the urine $(195 \mathrm{mg} / 24 \mathrm{~h}$ normal is $1-5 \mathrm{mg} / 24 \mathrm{~h}$ ), and after treatment with streptozotocin and Fluorouracil showed a subsequent decrease in the 5-HIAA level. Six months before the presence of liver metastases, the patient noted a lump in his left neck which proved to be a metastasis from the laryngeal primary tumor. A left-sided radical neck dissection was performed which showed involvement of multiple lymph nodes. Despite the fact that at last contact, the patient was alive 
and well, free of disease (Wenig, personal communication, 1990), the overall clinical course of this tumor indicated the aggressive nature of this neoplasm.

In general, carcinoid tumors have a checkered past-in the lung, for example, they were at one time grouped with the "bronchial adenomas" as benign tumors. Presently, pulmonary carcinoids are considered to be malignant lesions-though, obviously they are less aggressive tumors than the more common squamous carcinomas and adenocarcinomas of pulmonary origin. In lung, carcinoids typically have five-year survival rates of $87-100 \%[9,10]$. There is some preliminary evidence that the Ki-67 proliferation index may aid in the grading of pulmonary carcinoid tumors, although it may be less helpful in creating prognostic categories [11, 12].

Clearly, the behavior of the laryngeal typical carcinoid tumor is similarly not as innocuous as once thought. Laryngeal well-differentiated neuroendocrine carcinomas (typical carcinoids) are less aggressive than the more common moderately-differentiated neuroendocrine carcinomas (atypical carcinoids), although regional and distant metastases have been reported and may occur late in the disease course [3, 8, 13-16]. The potential sites of metastatic spread of this neoplasm include lymph nodes, liver, skin, lung, bone, pancreas [17]. The 5-year survival rate for typical carcinoid tumor of the larynx is $48.7 \%$ in a large series [3]. Based on this literature, we strongly recommend that that the terms "typical and atypical carcinoids" be abandoned for the more clinically and pathologically appropriate terms "well-differentiated and moderatelydifferentiated neuroendocrine carcinoma", respectively. We believe that these terms are much more accurately synchronized with the malignant potential and behavior that has been seen in these lesions in the larynx.

More work remains to be done with laryngeal welldifferentiated neuroendocrine carcinomas, and across the entire spectrum of neuroendocrine carcinomas in this rare subsite, with regard to classification, prognosis, and treatment. Additional studies, such as extending the work with proliferative markers in pulmonary carcinoids to laryngeal tumors, are going to be necessary. In any event, one thing remains clear: laryngeal well-differentiated neuroendocrine tumors ("typical carcinoid tumors") are malignant lesions that possess a well-demonstrated capacity for giving rise to both local and distant metastases. The nomenclature of this tumor should reflect this known clinical behavior.

\section{References}

1. Ferlito A, Silver CE, Bradford CR, Rinaldo A (2009) Neuroendocrine neoplasms of the larynx: an overview. Head Neck 31: 1634-1646

2. Korse CM, Taal BG, van Velthuysen ML, Visser O (2013) Incidence and survival of neuroendocrine tumours in the Netherlands according to histological grade: experience of two decades of cancer registry. Eur J Cancer 49:1975-1983

3. Soga J (2003) Carcinoids and their variant endocrinomas. An analysis of 11842 reported cases. J Exp Clin Cancer Res 22: 517-530

4. Ferlito A, Devaney KO, Rinaldo A (2006) Neuroendocrine neoplasms of the larynx: advances in identification, understanding, and management. Oral Oncol 42:770-788

5. Lewis JS Jr, Ferlito A, Gnepp DR, Rinaldo A, Devaney KO, Silver CE, Travis WD (2011) Terminology and classification of neuroendocrine neoplasms of the larynx. Laryngoscope 121: $1187-1193$

6. Soga J, Ferlito A, Rinaldo A (2004) Endocrinocarcinomas (carcinoids and their variants) of the larynx: a comparative consideration with those of other sites. Oral Oncol 40:668-672

7. Batsakis JG, el-Naggar AK, Luna MA (1992) Neuroendocrine tumors of larynx. Ann Otol Rhinol Laryngol 101:710-714

8. Wenig BM, Gnepp DR (1989) The spectrum of neuroendocrine carcinomas of the larynx. Semin Diagn Pathol 6:329-350

9. Fink G, Krelbaum T, Yellin A, Bendayan D, Saute M, Glazer M, Kramer MR (2001) Pulmonary carcinoid: presentation, diagnosis, and outcome in 142 cases in Israel and review of 640 cases from the literature. Chest 119:1647-1651

10. Travis WD, Rush W, Flieder DB, Falk R, Fleming MV, Gal AA, Koss MN (1998) Survival analysis of 200 pulmonary neuroendocrine tumors with clarification of criteria for atypical carcinoid and its separation from typical carcinoid. Am J Surg Pathol 22:934-944

11. Remes SM, Tuominen VJ, Helin H, Isola J, Arola J (2012) Grading of neuroendocrine tumors with $\mathrm{Ki}-67$ requires highquality assessment practices. Am J Surg Pathol 36:1359-1363

12. Walts AE, Ines D, Marchevsky AM (2012) Limited role of Ki-67 proliferative index in predicting overall short-term survival in patients with typical and atypical pulmonary carcinoid tumors. Mod Pathol 25:1258-1264

13. Zhang Q, Liu GQ, Ma Z (2013) Typical carcinoid tumor of the larynx with inguinal lymphatic metastasis. Zhonghua Er Bi Yan Hou Tou Jing Wai Ke Za Zhi 48:73-74 [Article in Chinese]

14. el-Naggar AK, Batsakis JG (1991) Carcinoid tumor of the larynx. A critical review of the literature. ORL J Otorhinolaryngol Relat Spec 53:188-193

15. Baugh RF, Wolf GT, Lloyd RV, McClatchey KD, Evans DA (1987) Carcinoid (neuroendocrine carcinoma) of the larynx. Ann Otol Rhinol Laryngol 96:315-321

16. Blok PH, Manni JJ, van den Broek P, van Haelst UJ, Slooff JL (1985) Carcinoid of the larynx: a report of three cases and a review of the literature. Laryngoscope 95:715-719

17. Soga J, Osaka M, Yakuwa Y (2002) Laryngeal endocrinomas (carcinoids and relevant neoplasms): analysis of 278 reported cases. J Exp Clin Cancer Res 21:5-13 